\title{
Insilico Docking Studies of Some Isolated Selected Compounds of Phoenix sylvestris (L.) Against Thrombosis
}

\author{
Md Alamgir Hossain ${ }^{1}$, Md Towhidul Islam Tarun ${ }^{2}$, Md. Anwar Morshed ${ }^{3}$, Md Salman Faisal ${ }^{4}$, \\ Whaheduzzaman ${ }^{5}$, Md Mostafa Moin Uddin ${ }^{6}$, Md Ershad ${ }^{1}$, Afzal Hosen ${ }^{1}$, Md AL Amin ${ }^{1}$ and Mohuya \\ Majumder*7,8 \\ ${ }^{1}$ Department of Chemistry, Jahangirnagar University, Bangladesh
}

${ }^{2}$ Department of Pharmacy, Jahangirnagar University, Bangladesh

${ }^{3}$ Department of Pharmacy, International Islamic University Chittagong

${ }^{4}$ Department of Pharmacy, Manarat International University, Bangladesh

${ }^{5}$ Department of Pharmacy, Jagannath University, Bangladesh

${ }^{6}$ Department of Chemistry, Chittagong University, Bangladesh

${ }^{7}$ Department of Pharmacy, East West University, Bangladesh

${ }^{8}$ GUSTO A Research Group, Bangladesh

*Corresponding author: Mohuya Majumder, Department of Pharmacy, East West University, Dhaka, Bangladesh

ARTICLE INFO

Received: 栔 July 26, 2019

Published: 㸷 August 02, 2019

Citation: Md Alamgir H, Md Towhidul Islam T, Aloke Soumya S, Md Salman F, Whaheduzzaman4, Md Mostafa M, Md Ershad, Afzal H, Md AL A, Mohuya M. Insilico Docking Studies of Some Isolated Selected Compounds of Phoenix sylvestris (L.) Against Thrombosis. Biomed J Sci \& Tech Res 20(2)-2019. BJSTR. MS.ID.003426.

Keywords: Phoenix sylvestris (L.); TISSUE PLASMINOGEN ACTIVATOR; Molecular docking; 4-methylcatechol

\begin{abstract}
Phoenix sylvestris (khejur palm) is a very graceful palm which is also known as Wild date palm, Silver date palm, date sugar palm and belongs to the family Arecaceae. The various parts of the plant reported possessing diuretic, analgesic effect, anti-inflammatory, antibacterial, thrombolytic and neuropharmacological activities. Phoenix sylvestris is traditionally claimed to have antidiabetic, antidiarrheal, anti-dysentery activity and used in the treatment of a toothache, menstrual complaint. Our aim of the study to performed molecular docking studies to identify potential binding affinities of the phytocompounds from Phoenix sylvestris, namely 4-methylcatechol towards TISSUE PLASMINOGEN ACTIVATOR for searching of the lead molecule against thrombus. A wide range of docking score found during molecular docking by Schrodinger. 4-methylcatechol and 2, 3-Dihydro-3,5dihydroxy-6-methyl-4H-pyran-4-one showed the docking score respectively $-6.077 \mathrm{~kJ} / \mathrm{mol}$ and $-5.378 \mathrm{~kJ} / \mathrm{mol}$ against TISSUE PLASMINOGEN ACTIVATOR. Between all the compounds 4-methylcatechol showed the best docking score towards TISSUE PLASMINOGEN ACTIVATOR. So, 4-methylcatechol is the best compound for TISSUE PLASMINOGEN ACTIVATOR enzyme inhibition, as it possessed the best value in Molecular Docking. Further, in vivo investigation needs to identify TISSUE PLASMINOGEN ACTIVATOR enzyme inhibitory activity of isolated compounds from Phoenix sylvestris.
\end{abstract}

\section{Introduction}

Thrombosis is the formation of a blood clot inside a blood vessel, obstructing the flow of blood through the circulatory system. A thrombus is more likely to occur in people who are immobile, and who are genetically predisposed to blood clotting. It can also form if an artery, vein, or surrounding tissue is damaged. A thrombus can block the flow of blood through a vein or artery if it detaches from the vessel wall and lodges in the lungs or other vital organs, it can become a life-threatening embolus [1]. Thrombolysis is the breakdown (lysis) of blood clots by pharmacological means, and commonly called clot busting. It works by stimulating secondary fibrinolysis by plasmin through infusion of analogs of tissue plasminogen activator (tPA), the protein that normally activates plasmin. Thrombolysis mainly involves the use of thrombolytic drugs, which dissolve blood clots 
[2]. The purpose of a fibrinolytic drug is to dissolve thrombin in acutely occluded coronary arteries thereby to restore blood supply to ischemic myocardium, to limit necrosis and to improve prognosis [3]. For the treatment of myocardial infarction, many thrombolytic agents are used. Among them, streptokinase is remarkable and widely used. Moreover, Tissue-type Plasminogen activator is more effective and safer than either urokinase or streptokinase type activators. It is noted that all available thrombolytic agents still have significant deficiencies, including the necessity of large doses to be maximally effective, limited fibrin specificity and a significant associated bleeding tendency. Therefore, steps are taken to develop improved recombinant variants of these drugs in order to minimize deficiencies of the available thrombolytic drugs [4-8].

The trend of using natural products has increased together with active plant extracts are normally for new drug discoveries [9]. Plants have been the time frame of countless traditional medicine systems across the world for thousands of years and continue and offer people with brand-new cures. Phoenix sylvestris Roxb. (Arecaceae), locally known as Khejur, is a palm tree cultivated for its syrupy juice and edible fruit in Bangladesh [10]. Palm is one of the important horticultural crops in many countries [11]. In Bangladesh, Khejur palm is produced as a homestead crop; however, it grows naturally or is cultivated in fallow lands, around homesteads, farmland boundary and even in the marginal lands along the roads and canals [12]. Fruits of the plant are used to treat back pain, stomachache, toothache, headache, arthritis, pain of buttocks, fever, piles, nervous debility, and as nervine tonic, restorative, sedative in ethnomedicine $[10,13]$. In addition, it is widely used as an aphrodisiac, sweetener and diuretic and in the treatment of vomiting, vertigo and unconsciousness. It improves cardiovascular health by soaking out all the cholesterol from the arteries. They have high calcium content and improve bone health. Generally, the juice of $P$. sylvestris is consumed as a cooling beverage [14]. The sap of Khejur palm is a good source of vitamins of the B group and contains, in addition, a variable amount of ascorbic acid [15], freshly harvested sap consists of sucrose around 10\%, minimal invert sugar of $<0.5 \%$ and a small amount of protein, gums, and minerals. Computational simulations of drug-target interactions using in silico molecular docking and molecular dynamics approaches are commonly used for the rational design and screening of drugs [16]. Molecular docking has become a major computational method for the prediction of ligand-receptor interactions [17]. A productive docking strategy must have the ability to adequately envision the local ligand represent the receptor limiting site (i.e. to find the trial ligand geometry inside a resistance confine) and the related physical-compound sub-molecular affiliations [18-20]. Furthermore, the aim of the study to find the mechanism of action of the isolated compounds from Phoenix sylvestris was explored the thrombolytic activity by molecular docking analysis.

\section{Materials and Methods}

\section{In silico Molecular Docking Protein Preparation}

Three-dimensional crystal structure of Catalytic domain of human two-chain tissue plasminogen activator complex of a bisbenzamidine (PDB id: 1A5H) was downloaded in pdb format from the protein data bank [21]. After that, the structure was prepared and refined using the Protein Preparation Wizard of SchrödingerMaestro v10.1. Charges and bond orders were assigned, hydrogens were added to the heavy atoms, selenomethionines were converted to methionines and all waters were deleted. Using force field OPLS_2005, minimization was carried out setting maximum heavy atom RMSD (root-mean-square-deviation) to $0.30 \AA$.

\section{Ligand Preparation}

The six major representative compound structures i.e., Diethyl nitrosamine (CID: 5921), 2, 3-Dihydro-3, 5-dihydroxy-6- methyl4H-pyran-4-one (CID: 119838), 4-methylcatechol (CID: 9958), 2,4-Di-tert-butyl phenol (CID: 7311) and Diethyl Phthalate (CID: 6781) were obtained from PubChem database. The ligands were prepared with Lig Prep tool embedded in Maestro 2015, neutralized at pH 7.0 \pm 2.0 using Epik and minimized by force field OPLS_2005.

\section{Receptor Grid Generation}

Receptor grids were calculated for prepared proteins such that various ligand poses bind within the predicted active site during docking. In Glide, grids were generated keeping the default parameters of van der Waals scaling factor 1.00 and charge cut off 0.25 subjected to OPLS 2005 force field. A cubic box of specific dimensions centered around the centroid of the active site residues (Reference ligand active site) was generated for the receptor. The bounding box was set to $14 \AA \times 14 \AA \times 14 \AA$ for docking experiments.

\section{Glide Standard Precision (SP) Ligand Docking}

SP flexible ligand docking was carried out in Glide of Schrödinger-Maestro v 10.1 [22]. Within which penalties were applied to non-cis/trans amide bonds. Van der Waals scaling factor and partial charge cutoff were selected to be 0.80 and 0.15 , respectively for ligand atoms. Final scoring was performed on energy-minimized poses and displayed as Glide score. The best- docked pose with lowest Glide score value was recorded for each ligand.

\section{Results \& Discussions}

\section{In silico Molecular docking analysis}

Prediction of interaction energies between ligand and receptor has been a major challenge for molecular docking [23]. Virtual screening utilizes docking and scoring of each compound from a dataset. The technique used is based on predicting the binding 
modes and binding affinities of each compound in the dataset by means of docking to an X-ray crystallographic structure [24]. Gridbased docking study was used to analyze the binding modes of molecules with the amino acids present in the active pocket of the protein [25].To identify the potential thrombolytic lead molecule, we have subjected the docking analysis of the active compounds of Phoenix sylvestris (L.)to the active site of TISSUE PLASMINOGEN ACTIVATOR. In order to study the interaction of the compounds with TISSUE PLASMINOGEN ACTIVATOR (PDB id: 1A5H). We performed Glide docking analysis by Schrodinger suitev10.1, where among of these compounds4-methylcatechol shows highest docking score against both enzymes.

Docking Score suggested that 4-methylcatechol and 2,3-Dihydro3,5-dihydroxy-6-methyl-4H-pyran-4-one had the highest affinity to the TISSUE PLASMINOGEN ACTIVATOR corresponding to the other compound. The results of docking analysis were described in Table 1 and the docking figure showed in Figure1. The results of docking analysis were described in Table 1 and the docking figure showed in Figure 1. The colors indicate the residue (or species) type: Redacidic (Asp, Glu), Green-hydrophobic (Ala, Val,Ile, Leu, Tyr, Phe, Trp, Met, Cys, Pro), Purple-basic (Hip, Lys, Arg), Blue-polar (Ser, Thr, Gln, Asn, His, Hie, Hid), Light gray-other (Gly, water), and Darker graymetal atoms. Interactions with the protein are marked with lines between ligand atoms and protein residues: Solid pink-H-bonds to the protein backbone, Dotted pink-H-bonds to protein side chains, Green-pi-pi stacking interactions, Orange-pi-cation interactions. Ligand atoms that are exposed to solvent are marked with gray spheres. The protein "pocket" is displayed with a line around the ligand, colored with the color of the nearest protein residue. The gap in the line shows the opening of the pocket.

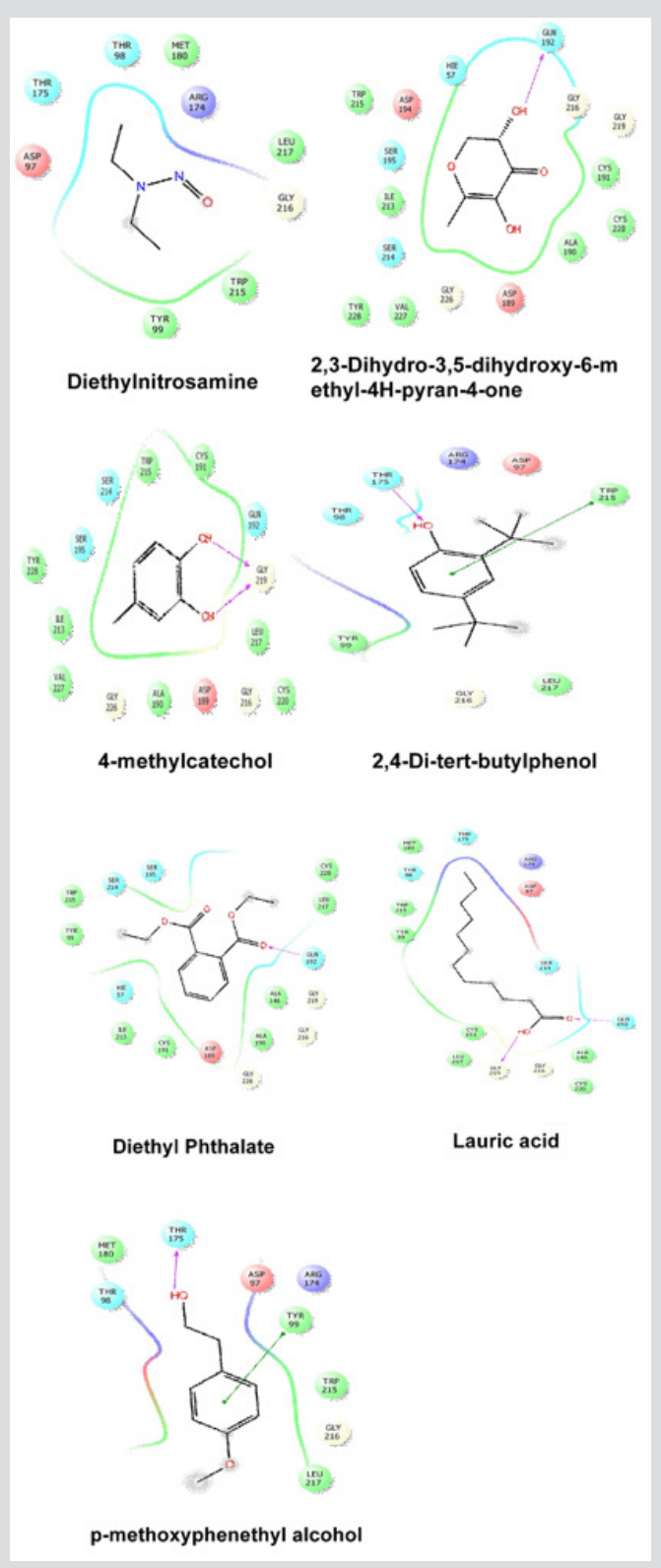

Figure 1: Schematic representation of the interactions between the best pose found of the selected compounds with TISSUE PLASMINOGEN ACTIVATOR (PDB ID: 1A5H). 
Table 1: Docking results of compounds diethyl nitrosamine(CID 5921),2,3-dihydro-3,5-dihydroxy-6-methyl-4H-pyran-4-one(CID 119838), 4-methylcatechol(CID 9958), 2,4-di-tert-butylphenol (CID 7311) and diethyl phthalate (CID 6781) with TISSUE PLASMINOGEN ACTIVATOR((PDB ID: 1A5H)).

\begin{tabular}{|c|c|c|c|}
\hline Compound Name & Compound Id & Docking Score & Glide Energy \\
\hline Diethyl nitrosamine & 5921 & -3.846 & -16.192 \\
\hline 2, 3-Dihydro-3,5-dihydroxy-6-methyl-4H-pyran-4-one & 119838 & -5.378 & -25.556 \\
\hline 4-methylcatechol & 9958 & -6.077 & -27.766 \\
\hline 2,4-Di-tert-butylphenol & 7311 & -4.39 & -22.267 \\
\hline Diethyl Phthalate & 6781 & -5.343 & -36.616 \\
\hline Lauric acid & 3893 & 1.155 & -32.048 \\
\hline p-methoxy phenethyl alcohol & 69705 & -4.003 & -23.878 \\
\hline
\end{tabular}

\section{Conclusion}

From the study, it was found that Phoenix sylvestris (L.) could be a great source of new TISSUE PLASMINOGEN ACTIVATOR activity. Insilco model support that all the isolated compound from $P$. sylvestris might be a TISSUE PLASMINOGEN ACTIVATOR inhibitor. Further in vivo investigation needs to identify the potential inhibitory activity of isolated compounds from P. sylvestris.

\section{Competing Interests}

The authors declare that they have no competing interests.

\section{Acknowledgment}

The authors thankful Mr. Arka jyoti Paul for providing the software and helping in manuscript writing.

\section{References}

1. Lyaker MR, Tulman DB, Dimitrova GT, Pin RH, Papadimos TJ (2013) Arterial embolism. Int J Crit Illn Inj Sci 3(1): 77-87.

2. Chowdhury TA, Kamal ATMM, Chowdhury KAA, Afrina J, Hossain H, et al. (2015) Cytotoxic \& thrombolytic activity of methanolic extract of Macaranga denticulata Bark. Pharma Innov 4(5): 36-39.

3. Morcos SK, Thomsen HS, Exley CM, ESUR M of CMSC of ES of UR (2005) Contrast media: interactions with other drugs and clinical tests. Eur Radiol 15(7): 1463-1468.

4. Nicolini FA, Nichols WW, Mehta JL, Saldeen TG, Schofield R, et al. (1992) Sustained reflow in dogs with coronary thrombosis with K2P, a novel mutant of tissue-plasminogen activator. J Am Coll Cardiol 20(1): 228235.

5. Marder VJ (1993) Recombinant streptokinase: Opportunity for an improved agent. Blood Coagul Fibrinolysis 4(6): 1039-1040.

6. Paul A, Majumder M, Gafur A, Sabrina Q Joy C, et al. (2017) Acoplamiento molecular para actividad trombólitica de algunos compuestos aislados de Clausena lansium. J Negat No Posit Results JONNPR 2(3): 115-119.

7. Lijnen HR, Van Hoef B, De Cock F, Okada K, Ueshima S, et al. (1991) On the mechanism of fibrin-specific plasminogen activation by staphylokinase. J Biol Chem 266(18): 11826-11832.

8. Adams DS, Griffin LA, Nachajko WR, Reddy VB, Wei CM (1991) A synthetic DNA encoding a modified human urokinase resistant to inhibition by serum plasminogen activator inhibitor. J Biol Chem 266(13): 8476-8482.

9. Lahlou M (2013) The success of natural products in drug discovery. Pharmacol Pharm 4(3): 17-31.

10. Ghani A (1998) Medicinal Plants of Bangladesh: Chemical Constituents and Uses. Asiatic society of Bangladesh pp. 467.
11. Chowdhury MSH, Halim MA, Muhammed N, Haque F, Koike M (2008) Traditional utilization of wild date palm (Phoenix sylvestris) in rural Bangladesh: an approach to sustainable biodiversity management. J For Res 19(3): 245-251.

12. Arntzen CJ (1994) Encyclopedia of Agricultural Science. RITTER, ELLEN M.

13. Acharya E, Pokhrel B (2006) Ethno-medicinal plants used by Bantar of Bhaudaha, Morang, Nepal. Our Nat 4(1): 96-103.

14. Jain P, Jain S, Sharma S, Paliwal S (2018) Diverse application of Phoenix sylvestris: A potential herb. Agric Nat Resour 52(2): 107-114.

15. Halim MD A, Chowdhury MSH, Muhammed N, Rahman M, Koike M. (2008) Sap production from khejur palm (phoenix sylvestris roxb) husbandry: a substantial means of seasonal livelihood in rural Bangladesh. For Trees Livelihoods 18(3): 305-318.

16. Jorgensen WL (2004) The many roles of computation in drug discovery. Science 303(5665): 1813-1818.

17. Kellenberger E, Rodrigo J, Muller P, Rognan D (2004) Comparative evaluation of eight docking tools for docking and virtual screening accuracy. Proteins Struct Funct Bioinforma 57(2): 225-242.

18. Arun Y, Saranraj K, Balachandran C, Perumal PT (2014) Novel spirooxindole-pyrrolidine compounds: Synthesis, anticancer and molecular docking studies. Eur J Med Chem 74: 50-64.

19. Sharma DC (2012) Biochemical Analysis and Molecular Characterization of wild India Date Palm, Phoenix Sylvestris L Roxb.

20. Jha KK, Khosa RL, Sangeeta Rani, Sudhir Chaudhary, Pradeep Singh, et al. (2011) Cressa Cretica Linn: An Important Medicinal Plant-A Review on Its Traditional Uses, Phytochemical and Pharmacological Properties 1(1): 91-100.

21. Berman HM, Westbrook J, Feng Z, Gilliland G, Bhat TN, et al. (2000) The protein data Bank nucleic acids research 28(1): 235-242.

22. Friesner RA, Banks JL, Murphy RB, Halgren TA, Klicic JJ, et al. (2004) Glide: a new approach for rapid, accurate docking and scoring. 1. Method and assessment of docking accuracy. J Med Chem 47(7): 1739-1749.

23. Babaheydari AK, Soureshjani EH, Salehi R (2013) Molecular Docking Analysis of Compounds Lavandula angustifolia Mill with Gabaa Receptor Lessen Stress 10(2).

24. Kumar A, Nisha CM, Silakari C, Sharma I, Anusha K, et al. (2016) Current and novel therapeutic molecules and targets in Alzheimer's disease. J Formos Med Assoc 115(1): 3-10.

25. Veeramachaneni GK, Raj KK, Chalasani LM, Annamraju SK, JS B, et al. (2015) Shape based virtual screening and molecular docking towards designing novel pancreatic lipase inhibitors. Bioinformation 11(12): 535-542. 


\section{ISSN: 2574-1241}

DOI: $10.26717 /$ BJSTR.2019.20.003426

Mohuya Majumder. Biomed J Sci \& Tech Res

(c) (P) This work is licensed under Creative

Submission Link: https://biomedres.us/submit-manuscript.php

$\begin{array}{ll}\text { BIOMEDICAL } & \text { Assets of Publishing with us } \\ \text { RESEARCHES } & \text { - Global archiving of articles } \\ & \text { - Immediate, unrestricted online access } \\ & \text { - Rigorous Peer Review Process } \\ \end{array}$

